\title{
Multi-Component Synthesis of Novel Diazoles: their Characterization and Biological Evaluation
}

\author{
Shad $\mathrm{HA}^{1 *}$, Hussain $\mathrm{A}^{1}$, Shahzad $\mathrm{K}^{1}$, Abeeha ${ }^{1}$, Hussain $\mathrm{G}^{2}$, Khan $\mathrm{ZI}^{3}$, Ahmad $\mathrm{K}^{3}$, Alam $\mathrm{MM}^{1}$ and Ilyas $\mathrm{M}^{1}$ \\ ${ }^{1}$ Department of Chemistry, Government Postgraduate College Jhang, Pakistan \\ ${ }^{2}$ Department of Chemistry, Government Postgraduate College Toba Tek Singh, Pakistan \\ ${ }^{3}$ Department of Botany, University of Sargodha, Pakistan
}

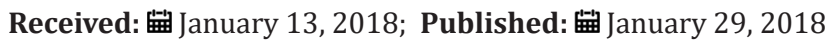

*Corresponding author: Hazoor Ahmad Shad, Department of Chemistry, Government Postgraduate College Jhang, Pakistan, Tel: +92 47 9200162; Email: hazoorahmad@gmail.com

\begin{abstract}
A new series of imidazoles were synthesized by multiple component system through condensation reaction of benzil, substituted aldehydes, substituted anilines and ammonium acetate. Glacial acetic acid was used as solvent. The bonding behavior and structure of the prepared compounds have been deduced from infra red spectroscopy, conduction method, and CHN analysis data. The synthesized imidazoles have been examined for in-vitro antibacterial properties. The results of these studies have shown that all compounds exhibited fair to major antibacterial activity against one or more bacterial strains.
\end{abstract}

Keywords: Imidazole; Biological Activity; Benzil; Aldehydes; Amines

\section{Introduction}

Multi-component reactions (MCRs) have been extensively used in organic synthesis and medicinal chemistry. These reactions show high synthetic efficiency and are further used for the preparation of complex compounds from simple reactants [1]. MCRs are also applied to the syntheses of tetra substituted imidazoles [2]. Tetra substituted imidazoles are very significant heterocyclic compounds in pharmaceutical and biochemical processes [3]. They are biologically active compounds having fungicidal [4], antiinflammatory [5], analgesic [6], antitumor [7] and antibacterial activities [8]. Substituted imidazoles are widely used as glucagon receptors [9], CB1 cannabinoid receptor antagonists [10] and modulators of P-glycoprotein (P-gp)-mediated multidrug resistance (MDR) agents [11]. It can also be employed as herbicides [12], fungicides and plant growth regulators [13]. Imidazoles as ionic liquids and imidazole related $\mathrm{N}$ - heterocyclic carbenes are extensively used as green solvents [14].

Hydroxyl phenyl group containing tetra-substituted imidazoles represent excellent excited-state intra-molecular proton transfer (ESIPT) material. These ESIPT materials have potential applications to laser dyes [15], electroluminescent materials [16], chemo sensors [17], and solar energy concentrators [18]. Thesynthesis ofimidazoles is of great significance in recent years due to their pharmacological and industrial applications. Number of synthetic procedures have been developed for the preparation of imidazoles mainly, multicomponent preparation which involve the condensation reaction of diketone, a hydroxyl ketone or a keto-monoxime with an aldehyde, primary amine and ammonium acetate using molecular iodine, BF3-SiO2, HClO4-SiO2, HY zeolite, silica gel/NaHSO4, InCl3.3H2O or potassium dodecatugstocobaltate trihydrate (K5CoW12040. 3H20) [19] as catalysts gave 1,2,4,5-tetrasubstituted imidazoles in significant yield. Recently, Ziarani et al., have synthesized 1,2,4,5-tetrasubstituted imidazoles in admirable yield using sulfonic acid functionalized silica ( $\mathrm{SiO} 2-\mathrm{Pr}-\mathrm{SO} 3 \mathrm{H}$ ) as a catalyst in solvent free conditions [20]. The merging of heterocyclic rings such as imidazoles and substituted imidazoles is an important strategy in the field of drugs and medicines. The high curative rate of related medicines and drugs encouraged the synthetic chemist to prepared large number of new chemotherapeutic compounds. In this study we have synthesized new 2-hydroxyphenyl containing tetra substituted imidazoles which can act as excellent ESIPT and bioactive material.

To the best of our knowledge, neither experimental nor the computational studies of the title molecules have been reported 
previously by any researcher. Therefore, in the present study we report the synthesis of three compounds; 1-(naphthalen-2yl)-2,4,5-triphenyl-1H-imidazole (1), 1-([1,1'-biphenyl]-4-yl)-2methyl-4,5-diphenyl-1H-imidazole (2) and 1-([1,1'-biphenyl]-4yl)-2-(furan-2-yl)-4,5-diphenyl-1H-imidazole (3) via condensation reaction represented in scheme 1 . These compounds 1,2 and 3 were structurally characterized through FT-IR, UV-Vis and other physical techniques. The primary theme of this study is to offer a comprehensive structural and spectroscopic description of the 1, 2 and 3 with the assistance of combined experimental and theoretical techniques.

\section{Materials and Methods}

The chemicals used in this project were of analytical grade and obtained from chemical suppliers. These were used without any further purification and treatment. All the solvents were also obtained from chemical suppliers and distilled before use. The completion of reaction was monitored through thin layer chromatography (TLC) using silica gel-G coated Al-plates $(0.5 \mathrm{~mm}$ thickness; Merk, Damastadt, Germany) and the plates were evaluated in iodine vapors.

\section{Instrumentation}

Magnetic stirrer hot plate was used for both heating and stirring the reaction mixture. The temperature range of hot plate was $\left(60-200{ }^{\circ} \mathrm{C}\right.$ ) and stirring range was (50 to $1200 \mathrm{rpm}$ ). The modal, AX200, Shimadzu, Japan was used for weighing the compounds. Gallen Kamp melting point apparatus was used for taking melting points of the synthesized compounds. IR Spectra of synthesized compounds was taken by using Agilent technology (Cary-620) FTRIR spectrophotometer. U.V/Visible spectra were recorded by using SHIMADZU UV 240 spectrophotometer. The conductivity of compounds was measured by using SDT-600 conductivity meter. Elemental analysis was determined on an EL III CHNOS elemental analyzer (Elementar, Hanau, Germany).

\section{General procedure for the preparation of compounds}

Synthesis of 1-(naphthalen-2-yl)-2,4,5-triphenyl-1Himidazole (1): For the synthesis of 1-(naphthalen-2-yl)-2,4,5triphenyl-1H-imidazole (1), benzil (1.05g, $0.005 \mathrm{mmol})$ and benzaldehyde $(0.53 \mathrm{~g}, 0.005 \mathrm{mml})$ were dissolved in $80 \mathrm{~mL}$ of glacial acetic acid at room temperature. $\alpha$-naphthylamine $(0.715 \mathrm{~g}$, $0.005 \mathrm{mmol})$ and ammonium acetate $(0.38 \mathrm{~g}, 0.005 \mathrm{mmol})$ was added subsequently. The mixture was refluxed for 8 hours at $110^{\circ} \mathrm{C}$. Reaction was monitored with thin layer chromatography (TLC). After the completation of reaction, colored solution was obtained. Volume of the solution was reduced to almost half by heating. Concentrated solution was then kept in a beaker for slow evaporation. Within a week, crystals of (1) imidazole were collected. The crystals were washed with ethyl acetate and then by ethyl alcohol. Same procedure was adopted for the synthesis of compounds (2) and (3).
1-(naphthalen-2-yl)-2,4,5-triphenyl-1H-imidazole Physical appearance: Grey crystalline solid; yield: 80 \%; m.p: $241{ }^{\circ} \mathrm{C}$; IR ( $\left.\mathrm{cm}^{-1}\right): 3058 \mathrm{sp}^{2}(\mathrm{C}-\mathrm{H}), 1654(\mathrm{C}=\mathrm{N}), 1448$ (C-N), 1593 $(\mathrm{C}=\mathrm{C}), 1593$; Conductivity: $21(\Omega-1 \mathrm{~cm} 2 \mathrm{~mol}-1)$; Elemental analysis: Calculated for C31H2N2 (422.519): C, 88.12; H, 5.25; N, 6.63\%. obtained: C, 88.01; H, 5.14; N, $6.43 \%$ (Figure 1).

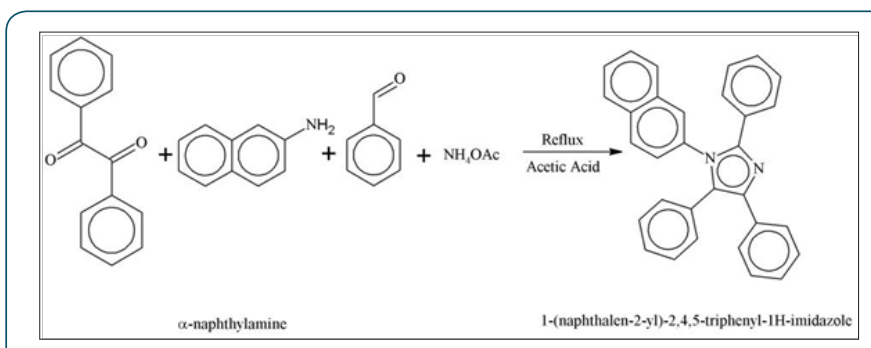

Figure 1: 1-(naphthalen-2-yl)-2,4,5-triphenyl-1H-imidazole.

1-([1,1'-biphenyl]-4-yl)-2-methyl-4,5-diphenyl-1 Himidazole (2): Physical appearance: yellow brown crystals; yield: 73\%; m.p: $210{ }^{\circ} \mathrm{C}$; IR (cm-1): 3063 sp2(C-H),2995 sp3 (C-H), 1654 (C=N), 1591 (C=C)1425, 1449 (C-N); Conductivity: 18 ( $\Omega$-1 cm2mol-1); Elemental analysis: Calculated for C28H22N2(386.48): C, 87.01; H,5.75; N,7.25 \%; Obtained: C, 86.95; H, 5.56; N, 7.11\% (Figure 2).

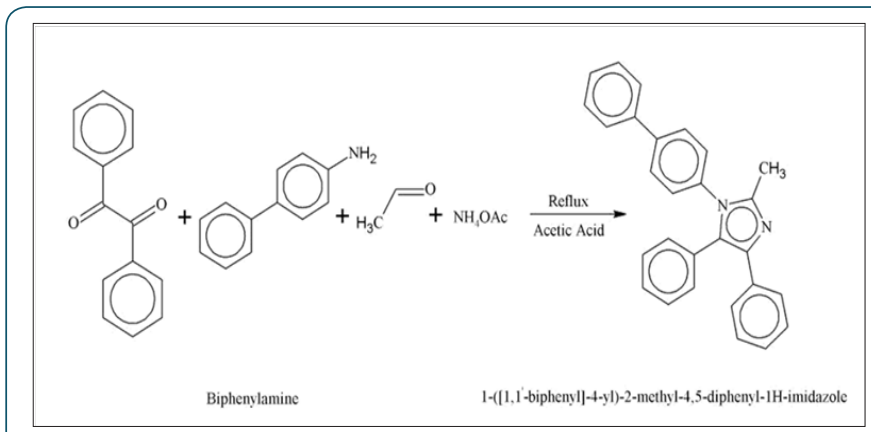

Figure 2: 1-([1,1'-biphenyl]-4-yl)-2-methyl-4,5-diphenyl-1H-imidazole.

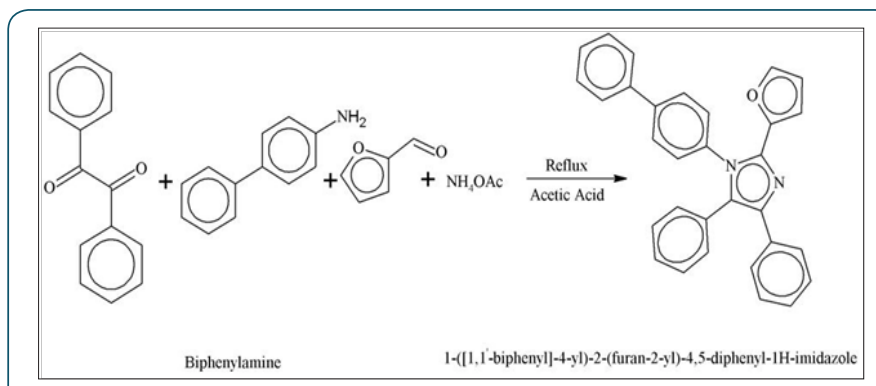

Figure 3: 1-([1,1'-biphenyl]-4-yl)-2-(furan-2-yl)-4,5-diphenyl-1H-imidazole (3).

1-([1,1'-biphenyl]-4-yl)-2-(furan-2-yl)-4,5-diphenyl-1Himidazole (3): Physical appearance: purple crystals; yield 78\%; m.p: $234{ }^{\circ} \mathrm{C}$; IR (cm H), $1654(\mathrm{C}=\mathrm{N}), 1591(\mathrm{C}=\mathrm{C}), 1477(\mathrm{C}-\mathrm{N})$, 1448 (C-O); Conductivity: 19 Elemental analysis: Calculated for C31H22N2O (438.51): C, 84.91; H, 5.06; N, Obtained: C, 84.73; H, 5.60; N, 6.25; 0, $3.55 \%$ (Figure 3). 


\section{Biological properties}

Antibacterial Activity (in-vitro): To find out the antibacterial activity of newly synthesized Diazoles (1)-(3), agar well diffusion method was used. The wells were dug out (about $6 \mathrm{~mm}$ in diameter) which were about $24 \mathrm{~mm}$ apart from each other by using a sterile steel borer. Bacterial inocula (about 2-8 h old) were spread on the surface of the nutrient agar with the help of a sterile cotton swab. The recommended concentration $(50 \mu \mathrm{g} / \mathrm{mL})$ of the imidazole compounds was prepared in DMSO and poured these solutions in the respective wells. For negative and positive controls, wells for DMSO and reference drug (Ciprofloxacin) were also prepared and put the respective solutions in these wells. The Petri dishes were put in the incubator at $37^{\circ} \mathrm{C}$. After $24 \mathrm{~h}$ antibacterial activity was determined by measuring the diameter (in $\mathrm{mm}$ ) of zones showing complete inhibition. The studies of alone DMSO showed no activity against any bacterial strains.

\section{Results and Discussions}

\section{Chemistry of Diazoles, (1)-(3)}

Diazoles, (1)--(3) were synthesized by condensation reaction of benzyl and aldehydes (such as benzaldehyde, furfural and acetaldehyde) with aromatic amines (such as $\alpha$-naphthylamine and biphenylamine) in the presence of sodium acetate. Glacial Acetic acid was used as solvent. To check reaction proceeding, thin layer chromatography was used after interval of times. The synthesized compunds were characterized by various physical methods such as IR-spectra, elemental analysis etc. The results obtained by different techniques were recorded.

\section{Physical characteristics}

Melting Point/Color/Physical Appearance: The newly synthesized diazoles are highly stable compounds towards moisture and air. They are crystalline solids in their appearance and possess different colors. They remain un-affected at room temperature

Table 3: Solubility Behavior of Diazole (1)--(3). because they have very high melting point. Melting points, physical appearance and color of imidazoles are shown in Table 1.

Table 1: Color, Melting Points and Physical appearance of the imidazole (1)--(3).

\begin{tabular}{|c|c|c|c|c|c|}
\hline No & Codes & Color & $\begin{array}{c}\text { Melting } \\
\text { point } \\
\left({ }^{\circ} \mathbf{C}\right)\end{array}$ & $\begin{array}{c}\text { Physical } \\
\text { appearance }\end{array}$ & Yield (\%) \\
\hline 1 & $(1)$ & Grey & 241 & Crystalline & 80 \\
\hline 2 & $(2)$ & $\begin{array}{c}\text { Yellow } \\
\text { brown }\end{array}$ & 210 & Crystalline & 73 \\
\hline 3 & $(3)$ & purple & 234 & Crystalline & 78 \\
\hline
\end{tabular}

Conductivity Measurements: The measured conductance of imidazole derivatives from (1) to (3) are shown in Table 2. The conductance of newly prepared compounds was measured at room temperature. In order to measure their conductivity, $1 \mathrm{M}$ solutions of the synthesized compounds were prepared in a DMSO. It was observed that synthesized compounds have lower values of conductance in the range from $18.0 \Omega-1 \mathrm{~cm} 2 \mathrm{~mol}-1$ to $21 \Omega-1 \mathrm{~cm} 2 \mathrm{~mol}-1$, since they are organic compounds of covalent nature having no ions.

Table 2: Conductance values of synthesized compounds.

\begin{tabular}{|c|c|c|}
\hline No. & Compounds & Conductance $\mathbf{( \Omega - 1} \mathbf{c m} \mathbf{2 m o l}-\mathbf{1})$ \\
\hline 1 & $(1)$ & 21 \\
\hline 2 & $(2)$ & 18 \\
\hline 3 & $(3)$ & 19 \\
\hline
\end{tabular}

\section{Solubility}

The Solubility of newly synthesized diazoles derivatives was observed in distilled water and some other organic solvents at hot and cold conditions. It was observed that all were completely soluble in ethanol and ethyl acetate but in other solvents they were either partially Soluble or insoluble. The solubility behavior of diazoles is shown in Table 3.

\begin{tabular}{|c|c|c|c|c|c|c|c|c|}
\hline No & Compounds & Ethanol & Methanol & Xylene & n- Hexane & Ethyl-acetate & $\begin{array}{c}\text { Petroleum- } \\
\text { ether }\end{array}$ & Water \\
\hline 1 & $(1)$ & S & PS & S & IS & S & SOH & IS \\
\hline 2 & $(2)$ & S & PS & IS & IS & S & PS & IS \\
\hline 3 & $(3)$ & S & SOH & PS & IS & S & IS & IS \\
\hline
\end{tabular}

$\mathrm{S}=$ soluble, $\mathrm{PS}=$ partially soluble, $\mathrm{IS}=$ insoluble, $\mathrm{SOH}=$ soluble on heating

\section{IR Spectra of Imidazole (1)-(3)}

Spectra of all synthesized imidazole (1) to (3) obtained and interpreted. The results and observations are discussed individually by each.

IR Spectra of 1-(naphthalen-2-yl)-2,4,5-triphenyl-1Himidazole (1): Selected IR values of compound (1) are given in experimental section. IR values obtained by imidazole showed that a new peak is appeared at $(1654 \mathrm{~cm}-1)$ which is due to $\mathrm{C}=\mathrm{N}$ stretching frequency. The appearance of this peak indicates that the expected imino bond might be formed by condensation of benzil with aromatic amine and aldehyde. A peak at (1593cm-1) may be due to $(\mathrm{C}=\mathrm{C})$ of aromatic imidazole ring. IR spectra also showed the appearance of a peak due to sp2 (C-H) bond at (3058). Another peak at $(1448 \mathrm{~cm}-1)$ was also appeared which may be due to (CN) stretching frequency. Carbonyl peak of benzil at $1680 \mathrm{~cm}-1$ was 
disappeared which showed that benzil was reacted completely. All other peaks were not changed and remained as such in reacting species.

IR Spectra of 1-([1,1'-biphenyl]-4-yl)-2-methyl-4,5diphenyl-1H-imidazole (2): Selected IR values of (2) are given in experimental. IR values obtained by the imidazole showed that a new peak is appeared at $\left(1654 \mathrm{~cm}^{-1}\right)$, due to $\mathrm{C}=\mathrm{N}$ stretching frequency. This peak indicates that expected imino bond might be formed by condensation of benzil, acetaldehyde and biphenylamine. Peak at (1680 cm-1) due to benzil carbonyl groups has disappeared, which indicates that benzil has reacted completely. Other peak at $(1449 \mathrm{~cm}-1)$ and was also observed which may be due to the appeared stretching frequencies of $\mathrm{u}(\mathrm{C}-\mathrm{N})$ moiety of (2). Peaks due to $(\mathrm{C}=\mathrm{C}), \mathrm{sp}^{2}(\mathrm{C}-\mathrm{H})$ and $\mathrm{sp}^{3}(\mathrm{C}-\mathrm{H})$ were also observed at $(1593 \mathrm{~cm}-1)$ $(3063 \mathrm{~cm}-1)$ and $(2995 \mathrm{~cm}-1)$. All these peaks indicate the formation of required product. Besides this, all other peaks are remained as such without any pronounced change as found in reacting species.

IR Spectra of 1-([1,1'-biphenyl]-4-yl)-2-(furan-2-yl)-4,5diphenyl-1 $\mathbf{H}$-imidazole (3): Selected IR values of synthesized compound (3) are given in experimental. The IR spectra of this compound showed change in the region of $(-\mathrm{C}=\mathrm{N})$ moiety, the obtained peak may be due to stretching observed at $(1654 \mathrm{~cm}$ $\left.{ }^{1}\right)$ region, whereas the band at $\left(1477 \mathrm{~cm}^{-1}\right)$ showed the (C-N) activity in the molecule (3).The bands observed may be due to the formation of $(\mathrm{C}-\mathrm{N})$ functional groups in the imidazole appeared at the $(1477 \mathrm{~cm}-1)$ peak regions. Formation of azomethine $(\mathrm{HC}=\mathrm{N})$ functional group may lead to the successful condensation reaction between benzil, aromatic aldehydes and aromatic amine taken as reaction reagents. Disappearing of peak at $1680 \mathrm{~cm}-1$ due to benzil shows that benzil has reacted in the reaction. IR spectra showed that peak at $\left(1448 \mathrm{~cm}^{-1}\right)$ was also appeared due to (C-0) stretching frequency. IR values for $\mathrm{C}=\mathrm{C}$ and $\mathrm{C}-\mathrm{H}$ were also obtained in spectra. All other bands remained as such without any prominent change.

\section{Pharmacology}

\section{Antibacterial Activity (in-vitro)}

Synthesized Diazoles (1)-(3) were tested against two Gram positive (Staphylococcus aureus and Bacillus subtilis) and one Gram negative (Escherichia coli) bacterial strains (Table 4) according to literature protocol $[21,22]$. The obtained data was compared with those of the standard drug Ciprofloxacin. Moderate to significant activity was observed against gram positive and gram negative bacterial strains by all synthesized compounds. The compound (1) exhibited highest antibacterial activity against all three strains. On contrary to this, the compound (2) exhibited lowest activity (15mm) against Escherichia coli. Overall the compounds (1) and (3) exhibited significant activity ( $>19 \mathrm{~mm}$ ) against all bacterial strains (Staphylococcus aureus), (Bacillus subtilis) and (Escherichia coli). Highest activity (22mm) was shown by compound (1) against Bacillus subtilis.
Table 4:Antibacterial Bioassay of Synthesized Diazoles, (1)-(3).

\begin{tabular}{|c|c|c|c|c|}
\hline \multicolumn{6}{|c|}{ Compound [Zone of Inhibition (Measured in millimeter)] } \\
\hline Bacterial Strains & $(1)$ & $(2)$ & $(3)$ & Ciprofloxacin \\
\hline \multicolumn{5}{|c|}{ Gram Positive } \\
\hline Staphylococcus aureus & 21 & 18 & 19 & 26 \\
\hline Bacillus subtilis & 22 & 17 & 19 & 28 \\
\hline \multicolumn{7}{|c|}{ Gram Negative } \\
\hline Escherichia coli & 20 & 15 & 20 & 26 \\
\hline
\end{tabular}

\section{Conclusion}

In the present study, novel tetra substituted diazoles (1-3) were synthesized by multi-component reaction (MCR) method. The characterization for chemical structures (1-3) was carried out by spectroscopic (FT-IR and UV-VIS) methods. In this project, in-vitro antibacterial activities were carried out by using different bacterial strains. The data exhibited that all synthesized compounds showed a moderate to significant activity against gram positive and gram negative bacterial strains.

\section{Acknowledgement}

One of us (Khurram Shahzad) is grateful to Mr. Abrar Ahmad, CEO, SRC (PVT) Ltd. Lahore to help us and providing facilities for obtaining IR spectra at their R \& D Labs. He is also thankful to Dr. Muhammad Shahid, Associate Professor, Department of Biochemistry, University of Agriculture, Faisalabad, Pakistan for helping us to study the antimicrobial activities in his labs.

\section{References}

1. Zhu J, Bienayme H (2006) Multi-component reactions. John Wiley \& Sons, USA.

2. Ahmad MS, Khalid M, Shaheen MA, Tahir MN, Khan MU, et al. (2018) Synthesis and XRD, FT-IR vibrational, UV-vis, and nonlinear optical exploration of novel tetra substituted Imidazole derivatives: A synergistic experimental-computational analysis. J Phys Chem Solids 115: 265-276.

3. Takle AK, Brown MJB, Davies S, Dean DK, Francis G, et al. (2006) The identification of potent and selective imidazole-based inhibitors of B-Raf kinase. Bioorg Med Chem Lett 16(2): 378-381.

4. Lombardino JG, Wiseman EH (1974) Preparation and antiinflammatory activity of some nonacidic trisubstituted imidazoles. J Med Chem 17(11): 1182-1188.

5. Sathe BS, Jaychandran E, Jagtap V, Sreenivasa G (2011) Synthesis characterization and anti-inflammatory evaluation of new fluorobenzothiazole schiff's bases. Int J Pharm Res Dev 3: 164-169.

6. Chohan ZH, Hazoor A Shad, Supuran CT (2012) Synthesis, Characterization and Biological Studies of Sulfonamide Schiff's Bases and some of their Metal Derivatives. J Enzy Inhib Med Chem 27(1): 5868.

7. Wittine K, Babic MS, Makuc D, Plavec J, Pavelic SK, et al. (2012) Novel 1,2,4-triazole and imidazole derivatives of L-ascorbic and iminoascorbic acid: Synthesis, anti-HCV and antitumor activity evaluations. Bioorg Med Chem 20(11): 3675-3685. 
8. Ganguly S, Vithlani VV, AK Kesharwani, R Kuhu, L Baskar, et al. (2011) Synthesis, antibacterial and potential anti-HIV activity of some novel imidazole analogs Acta Pharm 61: 187-201.

9. AK Takle, MJ Brown, S Davies, DK Dean, G Francis, et al. (2006) The identification of potent and selective imidazole-based inhibitors of B-Raf kinase. Bioorg Med Chem Lett 16: 378-381.

10. TF Gallagher, SM Fier-Thompson, RS Garigipati, ME Sorenson, JM Smietana, et al. (1995) 2,4,5-Triarylimidazole inhibitors of IL-1 biosynthesis. Bioorg Med Chem Lett 5: 1171-1176.

11. JH Lange, HH van Stuivenberg, HK Coolen, TJ Adolfs, AC McCreary, et al. (2005) Bioisosteric replacements of the pyrazole moiety of rimonabant: synthesis, biological properties, and molecular modeling investigations of thiazoles, triazoles, and imidazoles as potent and selective CB1 cannabinoid receptor antagonists. J. Med. Chem 48: 1823-1838.

12. MJ Newman, JC Rodarte, KD Benbatoul, SJ Romano, C Zhang, et al. (2000) Discovery and characterization of 0C144-093, a novel inhibitor of P-glycoprotein-mediated multidrug resistance, Cancer Res 60: 29642972.

13. R Schmierer, H Mildenberger, H Buerstell (1987) Preparation of phenylimidazoles as plant growth regulators. German Patent pp 361464.

14. VV Shynkar, AS Klymchenko, E Piemont, AP Demchenko, Y Mely (2004) Dynamics of intermolecular hydrogen bonds in the excited states of 4'-dialkylamino-3-hydroxyflavones. On the pathway to an ideal fluorescent hydrogen bonding sensor. J Phys Chem A 108: 8151-8159.

15. D Ma, F Liang, L Wang S Lee, L Hung (2002) Blue organic light-emitting devices with an oxadiazole-containing emitting layer exhibiting excited state intramolecular proton transfer. Chem. Phys. Lett 358: 24-28.
16. Y Ran, M Li, Z Z Zhang (2015) $\beta$-Cyclodextrin-Propyl Sulfonic Acid Catalysed One-Pot Synthesis of 1,2,4,5-Tetrasubstituted Imidazoles as Local Anesthetic Agents. Molecules 20: 20286-20296.

17. G M Ziarani, Z Dashtianeh, MS Nahad, A Badiei (2015) One-pot synthesis of 1,2,4,5-tetra substituted imidazoles using sulfonic acid functionalized silica (SiO 2-Pr-SO 3 H). Arabian J Chem 8: 692-697.

18. M Garcia-Melchor, AA Braga, A Lledos, G Ujaque, F Maseras (2013) Computational perspective on $\mathrm{Pd}$-catalyzed $\mathrm{C}-\mathrm{C}$ cross-coupling reaction mechanisms. Acc Chem Res 46: 2626-2634.

19. S Park, OH Kwon, S Kim, S Park, MG Choi, et al. (2005) Imidazole-based excited-state intramolecular proton-transfer materials: synthesis and amplified spontaneous emission from a large single crystal. J Am Chem Soc 127: 10070-10074.

20.D Sathiyanarayanan (2004) Vibrational Spectroscopy Theory and Application, New Age International Publishers, New Delhi, India.

21. Atta-ur-Rahman, Choudhary MI, Thomsen WJ (2001) Bioassay techniques for drug development. The Netherlands: Harwood Academic Publishers, United Kingdom.

22. McLaughlin JL, Chang CJ, Smith DL (1991) In: Atta-ur-Rahman (Ed) Studies in natural products chemistry, "Bentch-Top" bioassays for the discovery of bioactive natural products: An update, structure and chemistry (Part-B) 9

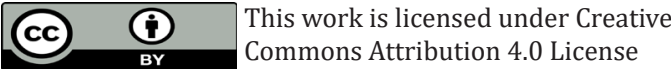

Submission Link:

Submit Article

DOI: 10.32474/AOICS.2018.01.000107

\section{AOICS}

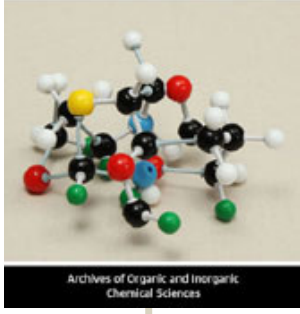

Archives of Organic and Inorganic Chemical Sciences

\section{Assets of Publishing with us}

- Global archiving of articles

- Immediate, unrestricted online access

- Rigorous Peer Review Process

- Authors Retain Copyrights

- Unique DOI for all articles 